\title{
Chronic intestinal pseudo-obstruction in systemic lupus erythematosus
}

G Perlemuter, S Chaussade, B Wechsler, P Cacoub, M Dapoigny, A Kahan, P Godeau, D Couturier

\begin{abstract}
BackgroundlAims-Chronic intestinal pseudo-obstruction (CIPO) reflects a dysfunction of the visceral smooth muscle or the enteric nervous system. Gastrointestinal manifestations are common in systemic lupus erythematosus (SLE) but CIPO has not been reported. Features of CIPO are reported in five patients with SLE.

Methods-From 1988 to 1993, five patients with SLE or SLE-like syndrome were hospitalised for gastrointestinal manometric studies. CIPO was the onset feature in two cases. Antroduodenal manometry (three hours fasting, two hours fed) was performed in all patients, and oesophageal manometry in four.
\end{abstract}

Results-Intestinal hypomotility associated with reduced bladder capacity and bilateral ureteral distension was found in four patients and aperistalsis of the oesophagus in three. Treatment, which consisted of high dose corticosteroids, parenteral nutrition, promotility agents, and antibiotics, led to remission of both CIPO and urinary abnormalities in all cases. Antroduodenal manometry performed in two patients after remission showed increased intestinal motility. One patient died, and postmortem examination showed intestinal vasculitis. Conclusions-CIPO in SLE is a life threatening situation that can be reversed by treatment. It may be: (a) a complication or onset feature of the disease; $(b)$ secondary to smooth muscle involvement; (c) associated with ureteral and vesical involvement; $(d)$ the result of intestinal vasculitis.

(Gut 1998;43:117-122)

Keywords: chronic intestinal pseudo-obstruction; systemic lupus erythematosus

Chronic intestinal pseudo-obstruction (CIPO) is a clinical syndrome characterised by ineffective intestinal propulsion. ${ }^{1}$ It can be caused by involvement of the visceral smooth muscle, the

Table 1 Clinical and immunological features of SLE

\begin{tabular}{|c|c|c|c|c|c|c|c|c|c|c|c|c|}
\hline \multirow[b]{2}{*}{ Case } & \multirow[b]{2}{*}{ Disease } & \multirow[b]{2}{*}{ Age (y) } & \multirow{2}{*}{$\begin{array}{l}\text { Prior } \\
\text { course } \\
\text { (years) }\end{array}$} & \multirow{2}{*}{$\begin{array}{l}\text { ACR } \\
\text { criteria }\end{array}$} & \multirow{2}{*}{$\begin{array}{l}\text { Weight } \\
\text { loss }(\mathrm{kg})\end{array}$} & \multicolumn{4}{|c|}{ Extradigestive features } & \multirow[b]{2}{*}{$A N A 1 /$} & \multirow{2}{*}{$\begin{array}{l}\text { Anti-dsDNA } \\
\text { antibody }\end{array}$} & \multirow{2}{*}{$\begin{array}{l}\text { Anti-ENA } \\
\text { antibody }\end{array}$} \\
\hline & & & & & & $R$ & $C$ & $N$ & $U$ & & & \\
\hline 1 & SLE-like & 19 & 0 & 3 & 10 & - & - & - & + & 320 & - & anti-RNP \\
\hline 2 & SLE & 28 & 7 & 5 & 5 & + & + & + & + & 4000 & 1000 & anti-Sm \\
\hline 3 & SLE & 29 & 0 & 3 & 25 & + & - & - & - & 100 & - & anti-RNP \\
\hline 4 & SLE & 34 & 1 & 6 & 40 & + & - & + & + & 400 & - & - \\
\hline 5 & SLE & 29 & 1 & 5 & 12 & + & + & - & + & 5000 & 80 & anti-RNP \\
\hline
\end{tabular}

ACR, American College of Rheumatology; R, rheumatological; C, cardiological; N, neurological; U, urological (reduced bladder capacity and bilateral ureteral distension); SLE, systemic lupus erythematosus. enteric nerves, or the visceral autonomic nervous system. It may be the primary disease or it may be secondary to a recognised underlying disease and then defined as secondary CIPO. The causes of secondary CIPO are numerous and involve the nervous, endocrine, and metabolic systems, intra-abdominal inflammation, infiltrative and connective tissue diseases, and drug induced states. $^{2}$ Mild gastrointestinal manifestations are common in systemic lupus erythematosus (SLE). Nausea, vomiting, diarrhoea, and abdominal pain are found in more than $50 \%$ of these patients. ${ }^{3}$ Motility disorders of the gastrointestinal tract are less frequent. CIPO is rare in SLE. Since our first published case ${ }^{4}$ four other patients with SLE have been hospitalised in our department with a diagnosis of CIPO, confirmed by manometry. We report here their clinical, biological, and manographic features.

\section{Materials and methods}

From 1988 to 1993 , five women, aged 19 to 39 (mean 33), were hospitalised for gastrointestinal manometric studies. Three were sent from a department of internal medicine because of food intolerance during SLE. The two other patients were hospitalised in a gastroenterology department for food intolerance, but no underlying disease was known to be present. All the patients had had the symptoms for at least six months before the manometric investigation. Between 1988 and 1993, 270 other antroduodenal or duodenojejunal manometries were performed in our department.

All the patients had abdominal pain, vomiting, abdominal distension, diarrhoea, constipation, and weight loss (table 1). In four cases, plain abdominal $x$ ray films showed gaseous distension of the small bowel and, in the upright films, the presence of fluid in the bowel loops (fig 1). Gastroscopy, colonoscopy, and small bowel series did not show any mechanical obstruction. The large loss of weight and the extradigestive features did not support a diagnosis of irritable bowel syndrome. A laparotomy was performed in patient 3 because
Leon-Malfreyt, 63003

Clermont-Ferrand

Cedex, France

M Dapoigny

Service de

Rhumatologie, Hôpital

Cochin

A Kahan

Correspondence to:

Professor S Chaussade.

Accepted for publication 19 January 1998 


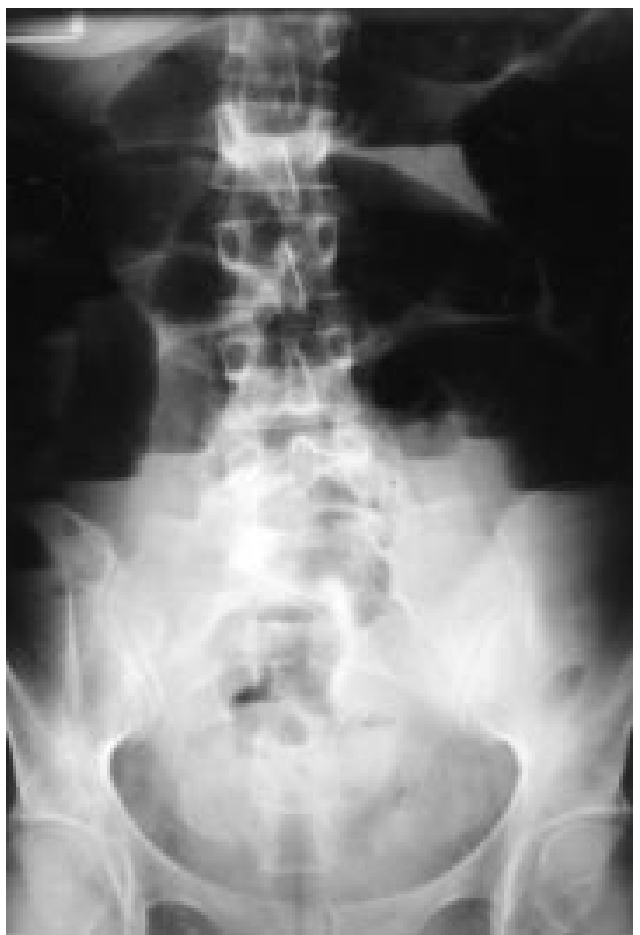

Figure 1 Plain abdominal radiograph (upright film). Gaseous distension of the small bowel with the presence of fluid in the bowel loops is observed.

of the extensive vomiting despite normal $x$ ray films. Everything was found to be normal. The association of symptoms and signs of mechanical bowel obstruction in the absence of an occluding lesion of the intestinal lumen are in accordance with the criteria of Schuffler et $a l^{2}{ }^{2}$ and Christensen et $a l,{ }^{5}$ for CIPO.

The diagnosis of SLE was made in three patients because of the presence of at least four of the criteria of the American College of Rheumatology (ACR). One had only three of the criteria, but the diagnosis of SLE was highly suggestive because of the association of arthralgia, positive antinuclear antibodies, hypocomplementaemia, positive lupus band test on normal unexposed skin, and IgG, C1q, IgA, and $\mathrm{C} 3$ deposits in the mesangial areas of the glomeruli. ${ }^{6}$ A diagnosis of Sjögren's syndrome was suggested for one patient because of the presence of five of the six criteria of the European Community ${ }^{7}$ : ocular symptoms, oral symptoms, ocular signs, focus score of 2 on minor salivary gland biopsy specimen, presence of serum antibodies to SS-A antigens, and presence of antinuclear antibodies. Nevertheless, the clinical picture of this patient was very close to SLE and can be considered as an SLE-like syndrome with three strong ACR criteria of SLE: persistent proteinuria greater than $0.5 \mathrm{~g}$ per day, haemolytic anaemia with reticulocytosis, and antinuclear antibodies.

Urinary echography and/or intravenous urography were carried out for all patients.

Manometric studies consisted of antroduodenal or small bowel manometry in all patients and oesophageal manometry in four. Gastrointestinal manometry was performed in each patient after a 12 hour fast. A multilumen perfusion tube was placed fluoroscopically with

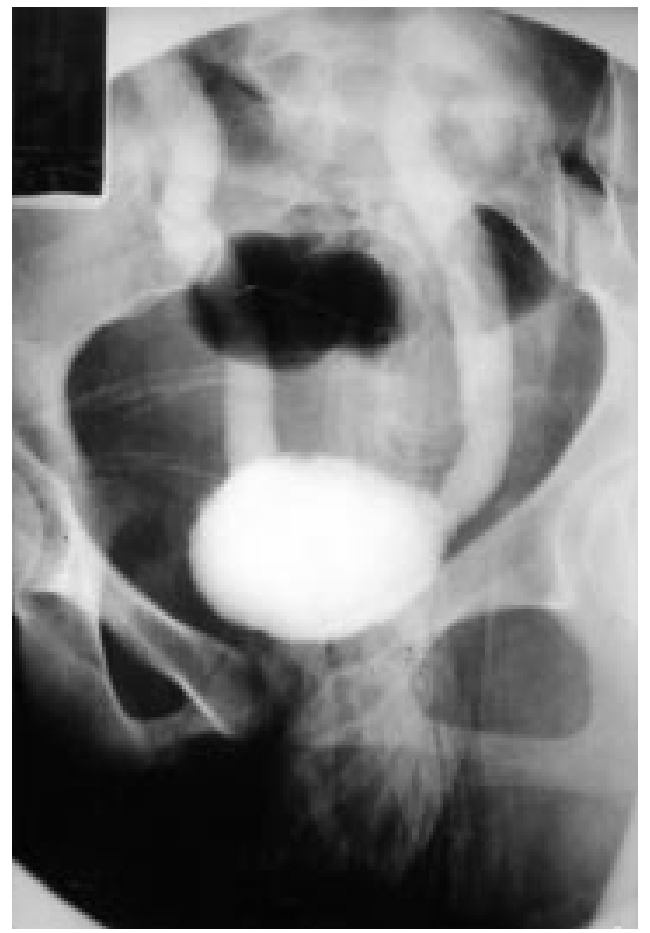

Figure 2 Urinary involvement during systemic lupus erythematosus and chronic intestinal pseudo-obstruction (intravenous urography). There is an increase in the thickness of the bladder wall with marked reduction in capacity associated with bilateral ureteral distension (patient 1).

the aid of a steerable catheter on the day before recording. In two patients, the perfusion tube consisted of four catheters which were positioned in the duodenum and the proximal jejunum $10 \mathrm{~cm}$ from each other. In the other three patients, the perfusion tube consisted of eight perfusion catheters (Arndorfer Instruments, Milwaukee, WI, USA). One side opening was made in each catheter. Three of these openings were $10 \mathrm{~cm}$ apart, with the distal port at $30 \mathrm{~cm}$ into the proximal jejunum. The remaining five openings were placed at $1 \mathrm{~cm}$ intervals and positioned across the antroduodenal junction. The eight catheters comprising a single manometric assembly were each perfused with distilled water via a low compliance pneumohydraulic pump (perfusion rate $0.1 \mathrm{ml} / \mathrm{min}$; perfusion pressure $96.6 \mathrm{kPa}$ ) and attached to a strain gauge transducer chart recorder (Astromed 2000) with a paper speed of 0.25 $\mathrm{mm} / \mathrm{second} .^{8} \mathrm{~A}$ radiograph of the abdomen was obtained on the day before and immediately before the recording to localise the position of the catheters. Recordings were obtained for three hours with the patient in the fasting state after a 12 hour fast and for two hours after ingestion of a standard mixed solid and liquid meal consisting of chicken, potatoes, butter, water $(24.3 \%$ protein, $55.5 \%$ carbohydrate, $20.2 \%$ fat, and $190 \mathrm{ml}$ water, total energy 511 kcal).

Intestinal manometric tracings were analysed visually as described previously. ${ }^{8}$ Abnormalities were identified by comparison with a large pool of similar manometric studies by the same experienced examiner (SC). Fasting tracings were evaluated for the presence of aberrant 
Table 2 Oesophageal manometry

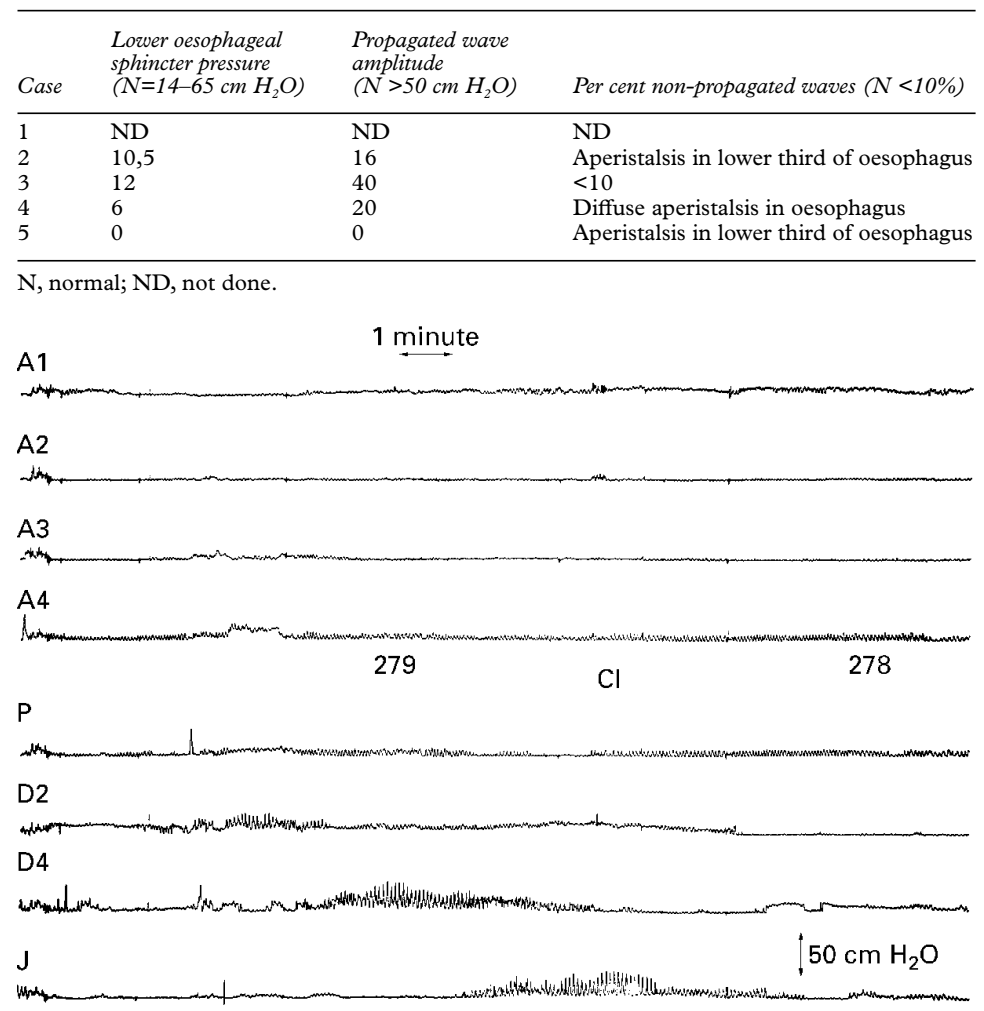

Figure 3 Fasting gastrointestinal motility tracings in patient 5. Intestinal hypomotility is observed with weak distal antral, duodenal, and jejunal contractions suggestive of a myopathic disorder. A, antrum (1 to 4, proximal to distal); P, pylorus; D2, descending duodenum; D4, distal duodenum; $\mathfrak{F}$, jejunum.

propagation and/or configuration of interdigestive migrating motor complex (MMC). For tracings obtained with the patient in the fed state, we looked for the ability of the ingested meal to change fasting intestinal activity into a fed pattern. ${ }^{8}$

\section{Results}

CHARACTERISATION OF PATIENTS

All the patients had nausea, vomiting, diarrhoea, and/or constipation. CIPO was the onset feature of SLE in two patients. In contrast, in the other three patients, CIPO was a complication occurring one, seven, and 11 years after SLE was diagnosed.

Four of the five patients had urological involvement with reduction of bladder capacity and bilateral ureteral distension (fig 2).

Oesophageal manometry was carried out in four patients (table 2). Peristalsis was found to be absent in the lower third of the oesophagus in two patients and over the entire length in one. The lower oesophageal sphincter pressure was decreased in all cases. Quantitative solid phase gastric emptying studies were performed in two patients using technetium- $99 \mathrm{~m}$ and showed delayed gastric emptying.

\section{MOTILITY OF THE STOMACH AND PROXIMAL} SMALL BOWEL (TABLE 3)

During the three hour fasting period, only one patient exhibited normal amplitude and duration of the propagated phase III of the MMC. The other four patients had low amplitude phase III of the MMC and duodenal or antroduodenal hypomotility with weak distal antral, duodenal, and jejunal contractions (fig 3). Hypomotility was characterised by low amplitude of contractions during phase III $\left(<20 \mathrm{~cm} \mathrm{H}_{2} \mathrm{O}\right)$ and infrequent contractions during phase II of the MMC (<one contraction every 20 minutes). ${ }^{9}$ Although patient 3 had a normal propagated phase III, gastric scintigraphy showed delayed gastric emptying. Postprandial small bowel motility was recorded in three patients. It was characterised in all cases by the absence of a normal postprandial pattern. The postprandial pattern observed in our patients was characterised by almost total lack of contractions during the two hours of recording. It was not possible to record postprandial motility in two patients because they started vomiting as soon as they were fed and could not tolerate further manometry.

Pharmacological stimulation of gastrointestinal motility was performed in all patients. Three different compounds were used when the patients were hospitalised: $100 \mathrm{mg}$ trimebutine intravenously ${ }^{10}$ and $100 \mu \mathrm{g}$ octreotide subcutaneously ${ }^{11}$ have been shown to induce phase III starting in the duodenum; erythromycin has been shown to stimulate antral motility and to induce phase III of the MMC starting in the antrum. ${ }^{12}$ The injections were performed five hours after the beginning of manometry - that is, after three hours fasting and two hours feeding. A dose of $500 \mathrm{mg}$ erythromycin alone or one hour after octreotide was given orally. The pharmacological stimulation increased digestive motility and generated phase III-like activity of the MMC with low amplitude of contractions in all patients except patient 3, in whom a normal phase III was recorded.

Table 3 Small bowel manometry

\begin{tabular}{|c|c|c|c|c|}
\hline \multirow[b]{2}{*}{ Case } & \multicolumn{2}{|c|}{ Fasting state } & \multirow[b]{2}{*}{$\begin{array}{l}\text { Fed state } \\
\text { hypomotility }\end{array}$} & \multirow[b]{2}{*}{ Pharmacological stimulation } \\
\hline & $\begin{array}{l}\text { Normal } \\
\text { PIII/3h }\end{array}$ & Hypomotility & & \\
\hline 1 & 0 & $\mathrm{~A}+\mathrm{D}$ & $\mathrm{A}+\mathrm{D}$ & $\begin{array}{l}\text { OCT: Low amplitude P III-like } \\
\text { ERY: Increased antral activity + low amplitude antral P III-like }\end{array}$ \\
\hline 2 & 0 & $\mathrm{~A}+\mathrm{D}$ & $\mathrm{A}+\mathrm{D}$ & $\begin{array}{l}\text { OCT: Low amplitude P III-like } \\
\text { ERY: Increased antral activity + low amplitude antral P III-like }\end{array}$ \\
\hline 3 & 1 & Normal & $\mathrm{ND}$ & TMB: Normal amplitude P III \\
\hline 4 & 0 & $\mathrm{D}$ & ND & TMB: Low amplitude antral P III-like \\
\hline 5 & 0 & $\mathrm{~A}+\mathrm{D}$ & $\mathrm{A}+\mathrm{D}$ & ERY: Increased antral activity + low amplitude antral P III-like \\
\hline
\end{tabular}

P III, phase III of the migrating motor complex; A, antrum; D, duodenum; ND, not done because of vomiting; OCT, octreotide 100 $\mu \mathrm{g}$ subcutaneously; ERY, erythromycin $500 \mathrm{mg}$ orally; TMB, trimebutine $100 \mathrm{mg}$ intravenously. 


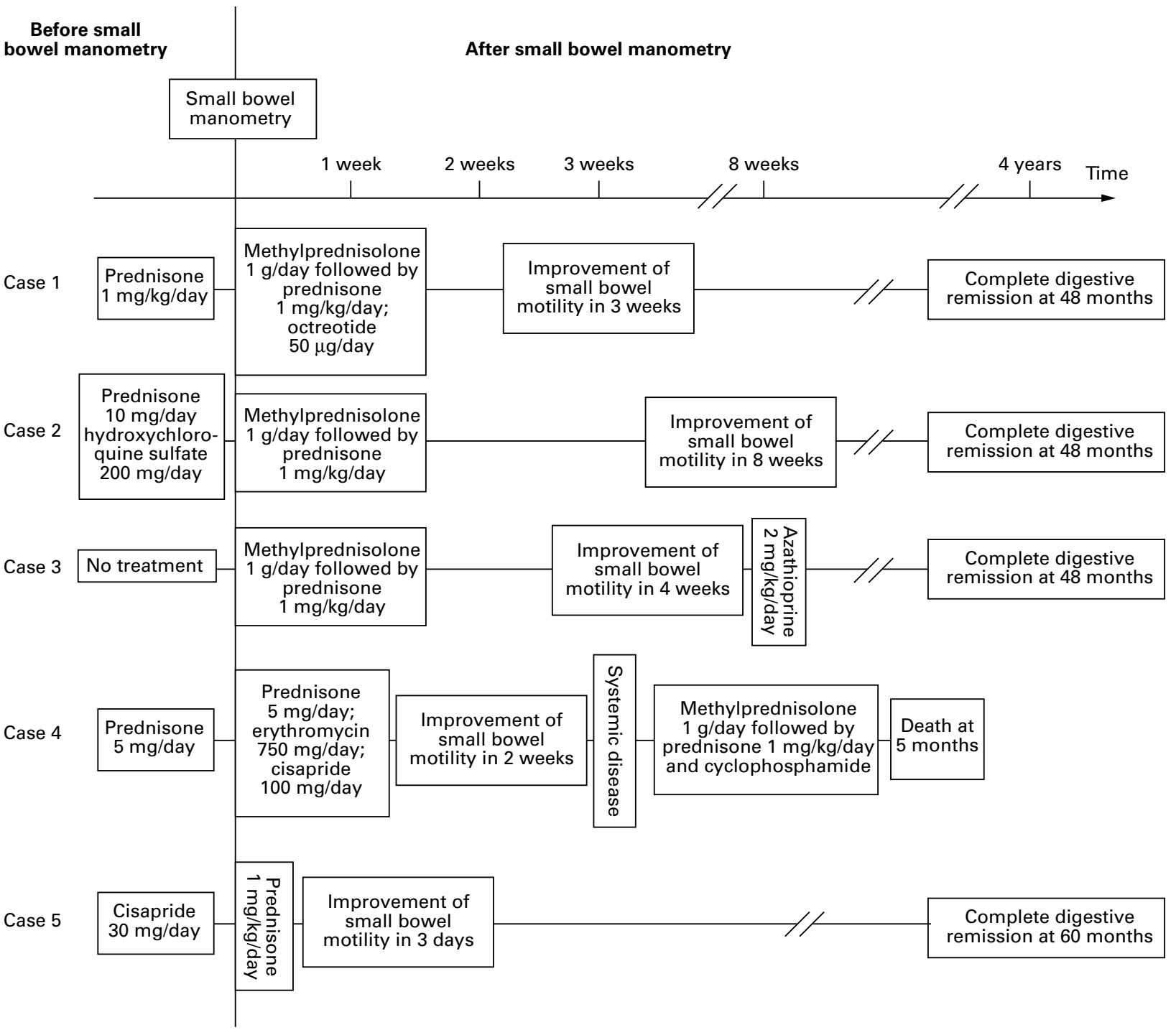

Figure 4 Treatment of patients and outcomes.

CLINICAL COURSE (FIG 4)

Treatment consisted in all patients of parenteral nutrition, and a six week oral antibiotic regimen. High dose immunosupression using a $1 \mathrm{~g} /$ day bolus of methylprednisolone for three days followed by prednisone $1 \mathrm{mg} / \mathrm{kg} /$ day orally was given for intestinal motility disorder in patients 1,2 , and 3. Patient 5 was treated with prednisone $1 \mathrm{mg} / \mathrm{kg} /$ day orally without bolus. Azathioprine $(2 \mathrm{mg} / \mathrm{kg} /$ day) was added to the regimen for patient 3 for renal involvement when oral feeding was resumed. A pharmacological stimulation of gastrointestinal motility using octreotide (50 $\mu \mathrm{g} /$ day subcutaneously) in patient 1 or cisapride $(100 \mathrm{mg} /$ day orally) plus erythromycin $(750 \mathrm{mg} /$ day orally) in patient 4 was started in response to the results of the small bowel manometry. Small bowel motility improved in all patients in three days to eight weeks. Diarrhoea and vomiting disappeared. Oral feeding resumed progressively with a low residue diet, and parenteral nutrition could be stopped in all patients after three, eight, four, two and two weeks in patients $1-5$ respectively. Patient 4 died from cerebromeningeal haemorrhage five months after the onset of digestive symptoms. It is interesting to note that she was the only patient not treated with high dose immunosupression for CIPO. She was treated with high dose methyprednisolone for neurological features four months after small bowel manometry when digestive symptoms had already disappeared. Postmortem examination showed severe lesions of both the oesophagus and the colon and an extensive fibrotic process in the muscularis layer, which was thin and contained a decreased number of smooth muscle cells. The innervation of the digestive wall was normal. There were inflammatory changes in the oesophagus with polymorphic cellular infiltration of mucosa and submucosa. An inflammatory cell infiltration associated with fibrinoid deposits was indicative of mild vasculitis in some vessels. Histological examination of the brain showed diffuse ischaemic lesions associated with marked vasculitis.

In the other four patients, administration of prednisone was tapered off after two months of digestive improvement. All four were still in remission in surveys conducted at $48,48,48$ and 60 months. Furthermore, bladder capacity 


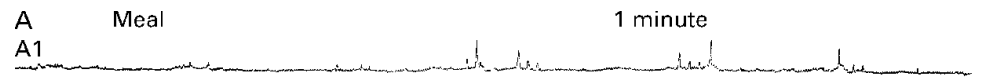

A2

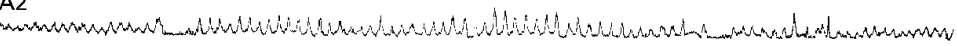

A3

A4

365

364

$P$

D2

D4
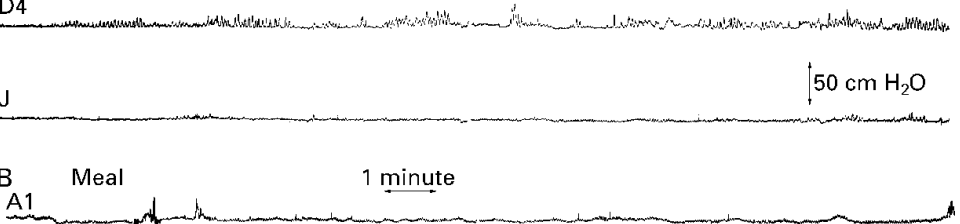

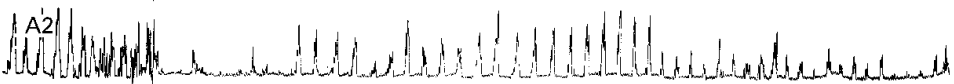

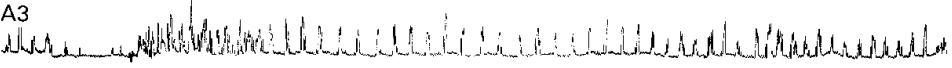

353

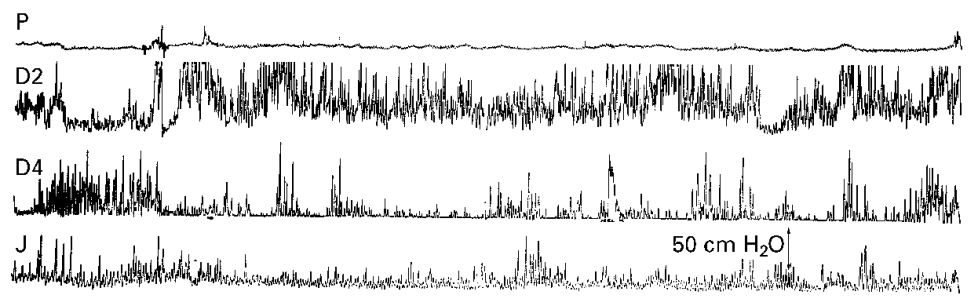

Figure 5 (A) Postprandial motility tracings before treatment (patient 1): a reduction in amplitude of gastrointestinal contractions can be seen. (B) Postprandial motility tracings after one year of treatment (patient 1): increased antral and intestinal motility can be seen. $A$, antrum (1 to 4, proximal to distal); P, pylorus; D2, descending duodenum; D4, distal duodenum; $\mathfrak{F}$, jejunum. nerves that control the visceral muscle. It is well known that progressive systemic sclerosis and dermatopolymyositis can be complicated by CIPO. ${ }^{13}{ }^{14}$ Moreover, although small bowel manometry has been used to study systemic sclerosis, ${ }^{15}$ it has never been performed in cases of SLE to our knowledge. Our study demonstrates that SLE should be added to the causes of CIPO. The present study also confirms the presence of significant postcibal antral and proximal small bowel hypomotility and reduced gastric emptying. These abnormalities may account for symptoms such as nausea, vomiting, and abdominal pain during SLE. ${ }^{16}$

Whereas oesophageal manometric abnormalities in SLE have been examined extensively, ${ }^{31718}$ manometric studies on the stomach and small bowel are few. ${ }^{3}$ Abnormalities of stomach and small bowel motility have been observed and include paralytic ileus and fluid in the bowel loops. ${ }^{19}$ CIPO is not mentioned in Dubois' lupus erythematosus as a manifestation of SLE. ${ }^{3}$ However, in our five symptomatic patients, four of five small bowel manometric examinations confirmed hypomotility. Moreover, postmortem examination in one showed an extensive fibrotic process in the muscularis layer without abnormality of innervation. These facts are suggestive of a myogenic type of CIPO. ${ }^{9}$ Pharmacological stimulation of intestinal motility can sometimes generate phase III of the MMC. Nevertheless, it is possible that physiopathology of CIPO during SLE is heterogeneous: one phase III of the MMC has been observed in one patient despite gastrointestinal symptoms, delayed gastric emptying at scintigraphy, and abnormalities at oesophageal manometry. Thus a neurological type of CIPO cannot be eliminated as reported for systemic sclerosis. ${ }^{8} 20$ Oesophageal aperistalsis may correlate with the presence of Raynaud's phenomenon ${ }^{21}$; we did not observe such a correlation in our study.

Four patients had urinary tract involvement with reduction of bladder capacity and bilateral ureteral distension. Urological manifestations of SLE are uncommon, ${ }^{22}$ and are often associated with gastrointestinal disorders such as diarrhoea, vomiting, malabsorption, ascite and protein losing enteropathy. ${ }^{23}{ }^{24}$ On the other hand, CIPO can be associated with urological abnormalities. ${ }^{52} \mathrm{~A}$ small reduction in bladder capacity, bilateral ureteral distension, low amplitude phase III of the MMC, and hypomotility $^{26}$ are criteria that must be taken into consideration in the diagnosis of extensive involvement of smooth muscle during SLE. It is interesting to note that the urinary tract was not involved in the only patient who had a normal antroduodenal manometric tracing. Postmortem examination of patient 4 showed inflammatory changes with fibrinoid deposits indicative of vasculitis of the digestive tract and of the brain. These lesions suggest smooth muscle involvement, itself secondary to vasculitis. ${ }^{27}{ }^{28}$ It is therefore not surprising that CIPO during SLE can lead to death: the survival rate in the largest published series of bowel vasculitis during SLE is less than $50 \% .^{29}{ }^{30}$ 
We conclude that CIPO can reveal or complicate SLE. It is a severe situation that can lead to death but which is potentially reversible with treatment. Manometric patterns and postmortem examination suggest smooth muscle involvement, itself secondary to vasculitis. CIPO in SLE can also be associated with oesophagus, bladder, and ureter involvement. High dose corticosteroids, parenteral nutrition, oral antibiotics, and pharmacological stimulation of small bowel motility are effective for both digestive and urinary tract symptoms.

1 Faulk DL, Anuras S, Christensen J. Chronic intestinal pseudoobstruction. Gastroenterology 1978;74:922-31.

2 Schuffler MD, Rohrmann CA, Chaffee RG, et al. Chronic intestinal pseudo-obstruction. A report of 27 cases and intestinal pseudo-obstruction. A report of 27 Case
review of the literature. Medicine 1981;60:173-96.

3 Weview of the literature. Medicine 1981;60:173-96. and biliary disorders. In: Wallace DJ, Hahn $\mathrm{BH}$, eds. and biliary disorders. In: Wallace DJ, Hahn BH, eds. Dubois' lupus erythematosus. 4th ed.
London: Lea \& Febiger, 1993:410-17.

4 Cacoub P, Benhamou Y, Barbet P, et al. Systemic lupus erythematosus and chronic intestinal pseudo-obstruction. $\mathscr{f}$ Rheumatol 1993;20:377-81

5 Christensen J, Dent J, Malagelada JR, et al. Pseudoobstruction. Gastroenterology International 1990;3:107-19.

6 Weiss RA, Mogavero HS, Synkowski DR, et al. Diagnostic tests clinical subsets in systemic lupus erythematosus: update 1983. Ann Allergy 1983;51:135-46.

7 Vitali C, Bombardieri S, Moutsopoulos HM, et al. Preliminary criteria for the classification of Sjögren's syndrome: results of a prospective concerted action supported by the European Community. Arthritis Rheum 1993;36:340-7.

8 Stanghellini V, Camilleri M, Malagelada JR. Chronic idiopathic intestinal pseudo-obstruction: clinical and intesidiopathic intestinal pseudo-obstruction: clinical

9 Anuras S, Anuras J, Bozeman T. Small intestinal manometric studies in patients with familial visceral myopathies. ric studies in patients with familial visceral m

10 Chaussade S, Grandjouan S, Couturier D, et al. Induction of phase 3 of the migrating motor complex in human small intestine. Eur f Clin Pharmacol 1987;32:615-18.

11 Soudah HC, Hasler WL, Owyang C. Effect of octreotide on intestinal motility and bacterial overgrowth in scleroderma. $N$ Engl f Med 1991;325:1461-7.

12 Annese V, Janssens J, Vantrappen G, et al. Erythromycin accelerates gastric emptying by inducing antral contractions and improved gastroduodenal coordination. Gastroenterology 1992;102:823-8.

13 Stafford-Brady FJ, Kahn HJ, Ross TM, et al. Advanced scleroderma bowel: complication and management. F Rheumatol 1988;15:869-74.
14 Klechner FS. Dermatomyositis and its manifestation in the gastrointestinal tract. Am $\mathcal{F}$ Gastroenterol 1970;53:141-4

15 Greydanus MP, Camilleri M. Abnormal postcibal antral and small bowel motility due to neuropathy or myopathy in systemic sclerosis. Gastroenterology 1989;96:110-15.

16 Camilleri M, Malagelada JR, Brown ML, et al. Relation between antral motility and gastric emptying of solids and liquids in humans. Am f Physiol 1985;149G:580-5.

17 Clark M, Fountain RB. Oesophageal motility in connective tissue disease. Br F Dermatol 1967;253:7630-4

18 Ramirez-Mata M, Reyes PA, Alarcon-Segovia D, et al. Esophageal motility in systemic lupus erythematosus. $A m \mathcal{F}$ Dig Dis 1974;19:132-6.

19 Brown CH, Shirley EK, Haserick JR. Gastrointestinal manifestations of systemic lupus erythematosus. Gastroenterology 1956;31:649-66.

20 Malagelada J-R, Camilleri M, Stanghellini V. Manometric diagnosis of gastrointestinal motility disorders. New York: Thieme-Stratton Inc, 1986:82-110.

21 Gutierrez F, Valenzuela JE, Ehresmann GR, et al. Esophageal dysfunction in patients with mixed connective tissue diseases and systemic lupus erythematosus. Dig Dis $\mathrm{Sci}$ 1982;27:592-7.

22 Orth RW, Weijman $\mathrm{MH}$, Cohen $\mathrm{AH}$, et al. Lupus cystitis: primary bladder manifestations of systemic lupus erythematosus. Ann Intern Med 1983;98:323-6.

23 Meulders Q, Michel C, Marteau P, et al. Association of chronic interstitial cystitis, protein-loosing enteropathy and paralytic ileus with seronegative systemic lupus erythematosus: case report and review of the literature. Clin Nephrol 1992;37:239-44.

24 Weisman MH, McDanald EC, Wilson CB. Studies of the pathogenesis of interstitial cystitis, obstructive uropathy, and intestinal malabsorption in a patient with systemic lupus erythematosus. Am f Med 1981;70:875-81.

25 Mann SD, Debinski HS, Kamm MA. Clinical characteristics of chronic idiopathic intestinal pseudo-obstruction in adults. Gut 1997;41:675-81.

26 Akhoue Y, Chaussade S, Guerre J, et al. Manométrie de l'intestin grêle dans le diagnostic des maladies motrices de l'intestin grêle: intérêt d'une stimulation pharmacologique l'intestin grêle: interêt d'une stimulation pharmacologique par la trime

27 Camilleri M, Pusey CD, Chadwick VS, et al. Gastrointestinal manifestations of systemic vasculitis. $Q \mathcal{f} \mathrm{Med}$ 1983;206:141-9.

28 Fauci AS, Haynes BF, Katz P. The spectrum of vasculitis. Clinical, pathologic, immunologic, and therapeutic considerations. Ann Intern Med 1978;89:660-76.

29 Zizic TM, Classen JN, Stevens MB. Acute abdominal complications of systemic lupus erythematosus and polyarteritis nodosa. Am F Med 1982;73:525-31.

30 Laing TJ. Gastrointestinal vasculitis and pneumatosis intestinalis due to systemic lupus erythematosus: successful treatment with pulse intravenous cyclophosphamide. $A m \mathcal{F}$ Med 1988;85:555-8. 